\title{
HPV and cofactors for invasive cervical cancer in Morocco: a multicentre case- control study
}

\author{
Mohamed Berraho ${ }^{*}$, Afaf Amarti-Riffi ${ }^{2}$, Mohammed El-Mzibri ${ }^{3}$, Rachid Bezad ${ }^{4,5}$, Noureddine Benjaafar ${ }^{6}$, \\ Abdelatif Benideer ${ }^{7}$, Noureddine Matar ${ }^{8}$, Zinab Qmichou ${ }^{3,9}$, Naima Abda ${ }^{1}$, Mohammed Attaleb ${ }^{3}$, Kaoutar Znati ${ }^{2}$, \\ Hind El Fatemi ${ }^{2}$, Karima Bendahhou ${ }^{10}$, Majdouline Obtel ${ }^{11}$, Abdelhai Filali Adib ${ }^{4}$, \\ Simone Mathoulin-Pelissier ${ }^{12,13}$ and Chakib Nejjari ${ }^{1}$
}

\begin{abstract}
Background: Limited national information is available in Morocco on the prevalence and distribution of HPV-sub-types of cervical cancer and the role of other risk factors. The aim was to determine the frequency of HPV-sub-types of cervical cancer in Morocco and investigate risk factors for this disease.

Methods: Between November 2009 and April 2012 a multicentre case-control study was carried out. A total of 144 cases of cervical cancer and 288 age-matched controls were included. Odds-ratios and corresponding confidence-intervals were computed by conditional logistic regression models.

Results: Current HPV infection was detected in $92.5 \%$ of cases and $13.9 \%$ of controls. HPV16 was the most common type for both cases and controls. Very strong associations between HPV-sub-types and cervical cancer were observed: totalHPV (OR = 39), HPV16 (OR = 49), HPV18 (OR = 31), and multiple infections (OR = 13). Education, high parity, sexual intercourse during menstruation, history of sexually transmitted infections, and husband's multiple sexual partners were also significantly associated with cervical cancer in the multivariate analysis.

Conclusions: Our results could be used to establish a primary prevention program and to prioritize limited screening to women who have specific characteristics that may put them at an increased risk of cervical cancer.
\end{abstract}

Keywords: Cervical cancer, Hpv, Determinants, Case-control study, Morocco

\section{Background}

Cervical cancer is the second most common cancer among women worldwide, with an estimated 529,409 incident cases and 274,883 deaths in 2008 [1]. More than $80 \%$ of new cases are currently diagnosed in developing countries [2].

Some sub-types of human papillomavirus (HPV) are the central and necessary cause of cervical cancer [3]. HPV infection appears to be a necessity but not a sufficient cause of cervical cancer [3]. The models of cervical pathogenesis involve persistent infection caused by

\footnotetext{
* Correspondence: maberraho@yahoo.fr

${ }^{1}$ Laboratory of Epidemiology, Clinical Research and Community Health, Faculty of Medicine and Pharmacy, University Sidi Mohammed Benabdellah, BP.1893Km 2.2 Route Sidi Harazem, Fez, Morocco

Full list of author information is available at the end of the article
}

high-risk HPV as well as cofactors that increase the risk of cervical cancer.

In Morocco, cervical cancer is the second most common cancer for women [4]. In 2008, the world agestandardized incidence of cervical cancer among women in Morocco was 14.1/100000 inhabitants/year [4] and the mortality rate was 8.4/100000 (1152) [2].

There is a lack of information on the prevalence and distribution of HPV sub-types of cervical cancer in Morocco as well as on the role of other risk factors for cervical cancer [5-8]. In Morocco, only one single center case-control study focusing on invasive cervical cancer was carried out in 1993 [9]. It demonstrated that HPV was the central cause of more than $90 \%$ of the cervical cancer cases, however; some methodological limitations have been noted such as the lack of matching 
for age. Also, the role of specific viral hosts or other factors (sociodemographic, behavioral and genetic) in the progression from infection to invasive disease has not been clarified for Moroccan women.

To assess the role of HPV infection and other associated factors in the development of cervical cancer, we have carried out a case-control study of invasive cervical cancer in Morocco.

\section{Methods}

\section{Study population}

Between November 2009 and April 2012, we performed our case-control study in three cities of Morocco: Rabat, Casablanca and Fez. A total of 144 patients with cervical cancer and 288 controls were included. The cases were recruited in three centers: the National Institute of Oncology of Rabat, the Oncology center of the Ibn Roshd University Hospital of Casablanca and the gynecologic centers of Hassan-II University Hospital of Fez. Inclusion criteria for cases included having a newly diagnosed, histologically confirmed cervical cancer, and having no previous cervical cancer treatment.

Controls were selected from both public outpatient gynecological hospitals and primary health-care centers with gynecological units. They were selected using an individual age-matching ( \pm 5 years). Exclusion criteria for controls included: diagnosis or history of cancer, history of hysterectomy, cervical conization or cervical cytologic abnormality.

\section{Data and specimen collection}

Protocols were approved by Ethical Review Committees of the Fez Faculty of Medicine and the Hassan-II University Hospital. Because of the high illiteracy rate among this population, we have not been able to administer a written information sheet. Instead, an explanation of its content has been given to the patients and their verbal consent have been gathered.

A trained nurse administered a standardized questionnaire to all participants. The questionnaire items concerned the socio-demographic characteristics, sexual behavior, genital hygiene, history of sexually transmitted diseases, reproductive and contraceptive history and smoking.

All patients received a pelvic examination performed by an oncologist or a gynecologist. For the cases, a tumor biopsy specimen was taken for HPV-DNA detection and typing and it was performed by an oncologist. For the controls, cervical exfoliated cells were obtained and followed by PAP-smear preparation. Besides, cervical specimens were placed in tubes with PBS for HPV-DNA detection and typing.

\section{Detection and typing of HPV-DNA}

The nested PCR-amplification of a conserved region of the HPV-L1 gene-DNA with the consensus MY09/ MY11 and GP5+/GP6+ primers followed by genotyping with direct DNA-sequencing, generally accepted as a scientific tool in research $[10,11]$ was used in our study.

For DNA-sequencing, the nested PCR products, if positive, were purified by PCR purification ExoSaP-IT clean-up system (USB-USA) and sequenced directly using GP6+ primer as the sequencing primer and BigDye ${ }^{\circ}$ Terminator v3.1 Cycle Sequencing Kit (AppliedBiosystems, Foster-city, CA-USA), according to manufacturer's protocol, on an ABI3130XL-DNA analyzer. Nucleotides sequences were aligned and compared with those of known HPV-sub-types available through GenBank by using the online BLAST 2.0 software server (https://www.ncbi.nlm.nih.gov/blast/).

\section{Statistical analysis}

First off, we describe the cases and controls according HPV infections and other factors. As age is an individual matching variable, for all other factors Odds-ratios and 95\% confidence intervals were calculated by means of conditional logistic regression.

In our bivariate analysis, we calculated adjusted OR for residence area and HPV infection (using a conditional logistic regression). In our population, the distribution of cases and controls by residence area was different. Thus, we consider it as a major confounding variable.

To assess the role of factors, other than HPV, we used a multivariate conditional logistic regression with reduction strategy. All variables statistically associated to cervical cancer in bivariate analysis, with the exception of HPV infection and residence area, were used in the multivariate analysis. $P=0.05$ was the level of statistical significance. Statistical analyses were performed with $\mathrm{SAS}^{\circledR}$ software 9.1.

\section{Results}

The mean age of the cases was $51.9 \pm 11.9$ years while the mean age of the controls $51.3 \pm 12.6(p=0.8)$. Among 144 cases, $96.4 \%$ were squamous cell carcinoma and $4.7 \%$ were adeno/adenosquamous carcinoma.

Diagnosis of the controls in the study was distributed as follows: gynecologic diseases $17.0 \%$, hypertension $13.8 \%$, gastrointestinal diseases $10.9 \%$, pelvic and other pain $10.6 \%$, general symptoms (fever, headache, asthenia....) $9.2 \%$, pregnancy control $8.1 \%$, diabetes $7.1 \%$, rheumatology diseases $6.0 \%$, respiratory diseases $4.2 \%$, dermatologic diseases $3.9 \%$, and other diagnosis $9.2 \%$.

\section{HPV infection}

HPV infection was detected in $92.5 \%$ of all cases $(92.2 \%$ of squamous cell carcinomas and $100 \%$ of adenocarcinomas) 
and in $13.9 \%$ of control women. Eight different HPV subtypes were identified in either single or multiple infections. HPV 16 was by far the most common type among cases as well as control women. Only HPV 16 infections were found among the 6 adenocarcinoma cases. Four controls and no cases were infected with low-risk HPV sub-types (Table 1).

The odds of cervical cancer was 39.3 times higher (95\% CI: 16.0-96.5) for women with HPV infection of any type compared to women without HPV (Table 2). The odds of cervical cancer was 49.3 times higher (95\% CI: 19.2-407.0) for women with HPV 16 infection compared to women without HPV (Table 2). The odds of cervical cancer was 31.7 times higher (95\% CI: 2.5407.0) for women with HPV 18 infection compared to women without HPV (Table 2).

\section{Sociodemographic and socioeconomic characteristics}

In the bivariate analysis (Table 3), an increased risk for cervical cancer was found among separated or divorced women (OR vs. married women =2.4). Non-educated women $(\mathrm{OR}$ vs. educated $=4.7)$, absence of health insurance $(\mathrm{OR}=3.8)$, residence in rural area $(\mathrm{OR}=10.7)$ and low socioeconomic level $(\mathrm{OR}=3.1$ vs. middle and high). After adjustment for residence area and HPV infection, only non-educated women (OR vs. educated women $=3.4)$, absence of health insurance $(\mathrm{OR}=3.1)$, and low socioeconomic level $(\mathrm{OR}=2.2)$ increased the risk of cervical cancer.

\section{Reproductive factors and contraceptive methods}

In the bivariate analysis (Table 4), women between 13 and 14 years or $\geq 15$ years at menarche had a higher risk than those who had an age at menarche $\leq 12$ (OR $=3.6$ and $\mathrm{OR}=2.4$ respectively). The number of pregnancies was also significantly associated with cervical cancer risk, where women with 4 and more pregnancies had a higher risk than those who had $\leq 3$ pregnancies $(\mathrm{OR}=1.4)$. Age at first pregnancy between 19 and 22 years (vs. $\leq 18$ years) increased the risk of cervical cancer $(\mathrm{OR}=2.2)$. Women reaching menopause at $<45$ years and between 45 and 49 years, compared to $\geq 50$ years, was associated with an OR of 3.3 and 3.2 respectively. Use of oral contraceptives $\geq 6$ years was associated with increase cervical cancer risk $(\mathrm{OR}=1.8)$. Women who had never used a condom had an increased risk for cervical cancer $(\mathrm{OR}=3.3)$. After adjustment for residence area and HPV infection, all associations observed in the bivariate analyses still significant except association between number of pregnancy, age at menopause and cervical cancer.

\section{Sexual behavior}

In the bivariate analysis (Table 5), the age at first sexual intercourse $<18$ years (OR vs. $\geq 18$ years $=2.4$ ) and having had $\geq 2$ lifetime sexual partners (OR vs. 1 sexual partner $=2.1$ ) were significant risk factors for

Table 1 Distribution of HPV infection by HPV type and multiplicity of infection among 133 cases of cervical cancer and 281 controls ${ }^{a}$

\begin{tabular}{|c|c|c|c|c|c|c|c|c|}
\hline & \multicolumn{2}{|c|}{ Total Cases } & \multicolumn{2}{|c|}{ Squamous cell carcinoma } & \multicolumn{2}{|c|}{ Adenocarcinoma } & \multicolumn{2}{|c|}{ Controls } \\
\hline & No. & $(\%)$ & No. & $(\%)$ & No. & $(\%)$ & No. & $(\%)$ \\
\hline Total HPV tested & 133 & 100 & 116 & 100 & 6 & 100 & 281 & 100 \\
\hline HPV Negative & 10 & 7.5 & 9 & 7.8 & - & - & 242 & 86.1 \\
\hline HPV Positive & 123 & 92.5 & 107 & 92.2 & 6 & 100 & 39 & 13.9 \\
\hline High risk $\mathrm{HPB}^{\mathrm{b}}$ & 123 & 92.5 & 107 & 92.2 & 6 & 100 & 35 & 12.5 \\
\hline Low risk HPV ${ }^{b}$ & - & - & - & - & & & 4 & 1.4 \\
\hline \multicolumn{9}{|l|}{ HPV types } \\
\hline Single infection & 118 & 88.7 & 102 & 87.9 & & & 33 & 11.7 \\
\hline 1 & - & - & - & - & - & - & 2 & 0.7 \\
\hline 6 & - & - & - & - & - & - & 1 & 0.4 \\
\hline 11 & - & - & - & - & - & - & 1 & 0.4 \\
\hline 16 & 108 & 81.2 & 92 & 79.2 & 6 & 100 & 14 & 5.0 \\
\hline 18 & 7 & 5.3 & 7 & 6.0 & - & - & 1 & 0.4 \\
\hline 31 & 1 & 0.8 & 1 & 0.9 & - & - & - & - \\
\hline 33 & 1 & 0.8 & 1 & 0.9 & - & - & 14 & 5.0 \\
\hline 35 & 1 & 0.8 & 1 & 0.9 & - & - & - & - \\
\hline Multiple infection & 5 & 3.8 & 5 & 4.3 & - & - & 6 & 2.2 \\
\hline $16 / 31$ & 4 & 3.0 & 4 & 3.4 & - & - & - & - \\
\hline $16 / 33$ & 1 & 0.8 & 1 & 0.9 & - & - & 5 & 1.8 \\
\hline $16 / 31 / 33$ & - & - & - & - & - & - & 1 & 0.4 \\
\hline
\end{tabular}


Table 2 HPV infection among 133 cases of cervical cancer and 281 controls

\begin{tabular}{|c|c|c|c|c|c|}
\hline & \multicolumn{2}{|c|}{ Cases } & \multicolumn{2}{|c|}{ Controls } & \multirow[t]{2}{*}{$\mathrm{OR}^{\mathrm{a}}(95 \% \mathrm{Cl})$} \\
\hline & No. & (\%) & No. & $(\%)$ & \\
\hline \multicolumn{6}{|l|}{ HPV } \\
\hline Negative & 10 & 7.5 & 242 & 86.1 & 1 \\
\hline Positive (any type) & 123 & 92.5 & 39 & 13.9 & $39.3(16.0-96.5)$ \\
\hline \multicolumn{6}{|l|}{ Multiple infection } \\
\hline No & 118 & 95.9 & 33 & 84.6 & 1 \\
\hline Yes & 5 & 4.1 & 6 & 15.4 & $0.2(0.02-1.7)$ \\
\hline \multicolumn{6}{|l|}{ HPV type } \\
\hline Negative & 10 & 7.5 & 242 & 86.1 & Reference \\
\hline 16 & 108 & 81.2 & 14 & 5.0 & $49.3(19.2-126.3)$ \\
\hline 18 & 7 & 5.3 & 1 & 0.4 & $31.7(2.5-407.0)$ \\
\hline HPV 1, 6, 11 & 0 & 0.0 & 4 & 1.5 & $<0.001(<0.001-999)$ \\
\hline $30 \mathrm{~s}(31,33,35)$ & 3 & 2.4 & 14 & 5.0 & $1.6(0.4-6.9)$ \\
\hline Multiple infection & 5 & 3.8 & 6 & 2.2 & $13.8(2.6-73.8)$ \\
\hline
\end{tabular}

aR: Non-adjusted Odd Ratio

cervical cancer. Women who had sexual intercourse during menstruation had an increased risk for cervical cancer $(\mathrm{OR}=4.3)$. Compared to women whose husband had one sexual partner, women whose husbands had two sexual partners and more had an increased risk for cervical cancer $(\mathrm{OR}=3.3)$. Compared to women who always washed the genital area after sexual intercourse, women who never or sometimes washed the genital area after intercourse had an increased risk for cervical cancer $(\mathrm{OR}=17.1)$. History of sexually transmitted infections was significantly associated with an increase risk of cervical cancer $(\mathrm{OR}=4.6)$. After adjustment for residence area and HPV infection, all associations observed in the bivariate analyses remained significant except the association between cervical cancer and the number of lifetime sexual partners for women.

\section{Other factors}

Regarding smoking status, only $2.1 \%$ of cases and $1.8 \%$ of controls had a smoking history $\leq 1$ packets/years (OR vs. never smoking $=1.4 ; 95 \% \mathrm{CI}=0.3-6.0$ ) while $2.8 \%$ and $0.3 \%$ of controls had a smoking $>1$ packets/years $(\mathrm{OR}$ vs. never smoking $=8.3 ; 95 \% \mathrm{CI}=0.9-74.9)$. We found no statistically significant associations between cervical cancer and family history of cancer.

\section{Multivariate analysis}

In the multivariate analysis (Table 6), an increased risk for cervical cancer was found among non-educated women (OR vs. educated $=4.6$ ), women with 4 and more

Table 3 Demographic and socio-economic characteristics among 144 cases of cervical cancer and 288 controls

\begin{tabular}{|c|c|c|c|c|c|c|}
\hline & \multicolumn{2}{|l|}{ Cases } & \multicolumn{2}{|l|}{ Controls } & \multirow{2}{*}{$\begin{array}{l}\mathrm{OR}^{\mathrm{a}} \\
(95 \% \mathrm{Cl})\end{array}$} & \multirow{2}{*}{$\begin{array}{l}\text { ORa } \\
(95 \% \text { Cl) }\end{array}$} \\
\hline & $\overline{\text { No. }}$ & $\overline{(\%)}$ & $\overline{\text { No. }}$ & $\overline{(\%)}$ & & \\
\hline Marital status & $n=144$ & & $n=288$ & & & \\
\hline Married & 86 & 59.7 & 209 & 72.6 & 1 & 1 \\
\hline Widowed & 36 & 25.0 & 58 & 20.1 & $1.7(0.9-3.0)$ & $1.5(0.7-2.9)$ \\
\hline Separated or divorced & 22 & 15.3 & 21 & 7.3 & $2.4(1.3-4.6)$ & $1.6(0.7-3.6)$ \\
\hline Health insurance & $n=138$ & & $n=283$ & & & \\
\hline Yes & 20 & 14.5 & 114 & 40.3 & 1 & 1 \\
\hline No & 118 & 85.5 & 169 & 59.7 & $3.8(2.2-6.6)$ & $3.1(1.7-5.5)$ \\
\hline Residence area & $n=143$ & & $n=271$ & & & \\
\hline Urban and sub-urban & 85 & 59.4 & 251 & 92.6 & 1 & \\
\hline Rural & 58 & 40.6 & 20 & 7.4 & $10.7(5.3-21.8)$ & \\
\hline Education & $n=134$ & & $n=273$ & & & \\
\hline Educated & 21 & 15.7 & 118 & 43.2 & 1 & 1 \\
\hline Non-educated & 113 & 84.3 & 155 & 56.8 & $4.7(2.6-8.4)$ & $3.4(1.1-11.0)$ \\
\hline Socioeconomic level & $n=133$ & & $n=279$ & & & \\
\hline Middle and high & 22 & 16.5 & 102 & 36.6 & 1 & 1 \\
\hline Low & 111 & 83.5 & 177 & 63.4 & $3.1(1.8-5.4)$ & $2.2(1.2-3.9)$ \\
\hline Work outside home & $n=144$ & & $n=288$ & & & \\
\hline Never & 131 & 91.0 & 245 & 85.1 & 1 & 1 \\
\hline Yes & 13 & 9.0 & 43 & 14.9 & $0.6(0.3-1.2)$ & $0.7(0.2-3.4)$ \\
\hline
\end{tabular}

aR: Non-adjusted Odd Ratio

${ }^{\mathrm{b} O R a:}$ Adjusted Odd Ratio for residence area and HPV infection 
Table 4 Reproductive factors, contraceptive methods and screening variables among 144 cases of cervical cancer and 288 controls

\begin{tabular}{|c|c|c|c|c|c|c|}
\hline & \multicolumn{2}{|l|}{ Cases } & \multicolumn{2}{|l|}{ Controls } & \multirow{2}{*}{$\begin{array}{l}\mathrm{OR}^{\mathrm{a}} \\
(95 \% \mathrm{Cl})\end{array}$} & \multirow{2}{*}{$\begin{array}{l}\text { ORa }^{\mathrm{b}} \\
(95 \% \mathrm{Cl})\end{array}$} \\
\hline & No. & $(\%)$ & No. & $(\%)$ & & \\
\hline Age at menarche (in years) & $n=140$ & & $n=257$ & & & \\
\hline$\leq 12$ & 25 & 17.9 & 103 & 40.1 & 1 & 1 \\
\hline $13-14$ & 78 & 55.7 & 90 & 35.0 & $3.6(2.1-6.2)$ & $3.6(1.9-6.9)$ \\
\hline$\geq 15$ & 37 & 26.4 & 64 & 24.9 & $2.4(1.3-4.4)$ & $2.6(1.3-5.5)$ \\
\hline No. of pregnancies & $n=141$ & & $n=276$ & & & \\
\hline$\leq 3$ & 40 & 28.4 & 119 & 43.1 & 1 & 1 \\
\hline$>3$ & 101 & 71.6 & 157 & 56.9 & $1.4(1.1-2.0)$ & $1.2(0.7-2.2)$ \\
\hline Age at first pregnancy & $n=130$ & & $n=254$ & & & \\
\hline$\leq 18$ & 52 & 40.0 & 99 & 39.0 & 1 & 1 \\
\hline $19-22$ & 55 & 42.3 & 60 & 23.6 & $2.2(1.2-3.9)$ & $2.2(1.1-4.4)$ \\
\hline$>22$ & 23 & 17.7 & 95 & 37.4 & $0.4(0.2-0.8)$ & $0.4(0.2-0.9)$ \\
\hline Age at last pregnancy & $n=120$ & & $n=228$ & & & \\
\hline$\leq 35$ & 67 & 55.8 & 119 & 52.2 & 1 & 1 \\
\hline$>35$ & 53 & 44.2 & 109 & 47.8 & $0.9(0.6-1.5)$ & $0.9(0.5-2.3)$ \\
\hline Menopause & $n=142$ & & $n=278$ & & & \\
\hline No & 66 & 53.5 & 129 & 46.4 & 1 & 1 \\
\hline Yes & 76 & 46.5 & 149 & 53.6 & $1.1(0.6-2.2)$ & $1.0(0.5-2.9)$ \\
\hline \multicolumn{7}{|l|}{ Age at menopause } \\
\hline$\geq 50$ & 29 & 40.3 & 93 & 66.0 & 1 & 1 \\
\hline $45-49$ & 26 & 36.1 & 28 & 19.9 & $3.2(1.3-7.6)$ & $4.2(0.9-16.5)$ \\
\hline$<45$ & 17 & 23.6 & 20 & 14.2 & $3.3(1.2-9.2)$ & $2.5(0.8-7.9)$ \\
\hline Years of use of oral contraceptives & $n=140$ & & $n=277$ & & & \\
\hline$<6$ & 85 & 60.7 & 201 & 72.6 & 1 & 1 \\
\hline$\geq 6$ & 55 & 39.3 & 76 & 27.4 & $1.8(1.2-2.8)$ & $1.9(1.2-3.1)$ \\
\hline Use of injectable contraceptives & $n=288$ & & $n=141$ & & & \\
\hline No & 135 & 95.7 & 277 & 96.2 & 1 & 1 \\
\hline Yes & 6 & 4.3 & 11 & 3.8 & $1.1(0.4-2.9)$ & $1.0(0.3-3.0)$ \\
\hline Condom use & $n=139$ & & $n=284$ & & & \\
\hline Yes & 12 & 8.6 & 69 & 24.3 & 1 & 1 \\
\hline No & 127 & 91.4 & 215 & 75.7 & $3.3(1.8-6.4)$ & $3.2(1.5-6.8)$ \\
\hline
\end{tabular}

${ }^{\mathrm{a} O R: ~ N o n-a d j u s t e d ~ O d d ~ R a t i o ~}$

bORa: Adjusted Odd Ratio for residence area and HPV infection

pregnancies (OR vs. $\leq 3$ pregnancies $=1.7$ ), women who had sexual intercourse during menstruation $(\mathrm{OR}=9.9)$, women whose husband had multiple sexual partners (OR vs. women whose husband had one sexual partner $=2.9$ ) and women who had a history of sexually transmitted infections $(\mathrm{OR}=11.1)$.

\section{Discussion}

This case-control study provides information on the risk factors for cervical cancer and the infection of HPV in Morocco. The results confirm the finding of the investigators indicating that HPV DNA is present in the vast majority of cervical cancers $(92.5 \%)[12,13]$. Odd ratios linked to HPV sub-types demonstrated very strong associations for total HPV (OR = 39.3), HPV 16 (OR = 49.3), HPV 18 (OR = 31.7), and multiple infections ( $\mathrm{OR}=13.8)$. In this study, the other identified determinants of invasive cervical cancer were high parity, low educational level, husband's multiple sexual partners, sexual intercourse during menstruation and history of sexually transmitted infections.

\section{HPV and cervical cancer}

All HPV infections in cervical cancer cases were a high risk. This finding is similar to that found in other worldwide [3] or Moroccan studies [9]. HPV 16 in single or 
Table 5 Women sexual characteristics, Sexually Transmitted Infections and hygienic practices among 144 cases of cervical cancer and 288 controls

\begin{tabular}{|c|c|c|c|c|c|c|}
\hline & Cases & & Controls & & $\mathrm{OR}^{\mathrm{a}}$ & $\mathrm{ORa}^{\mathrm{b}}$ \\
\hline & No. & $(\%)$ & $\overline{\text { No. }}$ & $(\%)$ & & \\
\hline Age at first intercourse (years) & $n=132$ & & $n=272$ & & & \\
\hline$\geq 18$ & 59 & 44.7 & 170 & 62.5 & 1 & 1 \\
\hline$<18$ & 73 & 55.3 & 102 & 37.5 & $2.4(1.5-3.9)$ & $2.3(1.3-3.9)$ \\
\hline No. of lifetime sexual partners & $n=135$ & & $n=272$ & & & \\
\hline 1 & 107 & 79.2 & 241 & 88.6 & 1 & 1 \\
\hline$\geq 2$ & 28 & 20.8 & 31 & 11.4 & $2.1(1.2-3.8)$ & $1.7(0.8-3.4)$ \\
\hline Sexual intercourse during menstruation & $n=138$ & & $n=280$ & & & \\
\hline No & 99 & 71.7 & 256 & 91.4 & 1 & 1 \\
\hline Yes & 39 & 28.3 & 24 & 8.6 & $4.3(2.4-7.9)$ & $4.7(2.3-9.7)$ \\
\hline Husband's number of sexual partners & $n=129$ & & $n=269$ & & & \\
\hline One & 67 & 51.9 & 210 & 78.1 & 1 & 1 \\
\hline Two and more & 62 & 48.1 & 59 & 21.9 & $3.3(2.1-5.2)$ & $2.8(1.3-6.3)$ \\
\hline History of Sexually Transmitted Infections & $n=138$ & & $n=270$ & & & \\
\hline No & 123 & 89.1 & 262 & 97.0 & 1 & 1 \\
\hline Yes & 15 & 10.9 & 8 & 3.0 & $4.6(1.6-12.9)$ & $6.7(1.9-23.6)$ \\
\hline History of herpes infection & $n=139$ & & $n=273$ & & & \\
\hline No & 133 & 95.7 & 257 & 94.1 & 1 & 1 \\
\hline Yes & 6 & 4.3 & 16 & 5.9 & $0.7(0.3-1.9)$ & $0.6(0.3-2.1)$ \\
\hline History of condyloma infection & $n=139$ & & $n=281$ & & & \\
\hline No & 133 & 95.7 & 274 & 97.5 & 1 & 1 \\
\hline Yes & 6 & 4.3 & 7 & 2.5 & $1.6(0.5-4.9)$ & $1.4(0.4-5.2)$ \\
\hline Genital washing after intercourse & $n=138$ & & $n=270$ & & & \\
\hline Always & 51 & 37.0 & 241 & 89.3 & 1 & 1 \\
\hline Sometimes or never & 87 & 63.0 & 29 & 10.7 & $17.1(8.2-35.4)$ & $18.6(7.9-43.7)$ \\
\hline
\end{tabular}

${ }^{a}$ OR: Non-adjusted Odd Ratio

${ }^{\mathrm{b}}$ ORa: Adjusted Odd Ratio for residence area and HPV infection

multiple infections was by far the most common type since it has been found in $85.0 \%$ of cervical cancer cases. Overall, these findings suggest that the distribution of HPV sub-types in cervical cancer in Morocco resembles more closely to the distribution found in similar studies in Europe and North America than in the rest of the African continent, where HPV 16 accounts for less than $50 \%$ of HPV positivity $[13,14]$. This difference can be explained by the geographic location, socioeconomic and sociocultural characteristics of Morocco. Indeed, it is a country located in North Africa, it has maritime border with Europe. Its cultural transition is mainly marked by Westernization. There was a variation in HPV-specific prevalence between different histological cancer types, HPV 16 was found in all adenocarcinoma and in $79.2 \%$ of squamous cell carcinoma; this result is similar to that found in North Africa and South America where HPV 16 was found in $72 \%$ of the adenocarcinoma cases [15]. However, worldwide HPV 16 was identified in $55.2 \%$ of squamous cell carcinoma and in $31.3 \%$ of adenocarcinoma [13]. Only $6.0 \%$ of squamous cell carcinoma cases and no adenocarcinoma cases were infected with HPV 18, which disagrees with other studies in which it is reported that throughout the world, HPV 18 is present in $12.3 \%$ of squamous cell carcinoma [13] and $37.7-39.0 \%$ in adenocarcinoma $[13,15]$. The fraction of squamous cell carcinoma attributable to HPV 16 and 18 was $74.8 \%$ while that for adenocarcinoma was $85.8 \%$, almost the same as reported worldwide [16].

The frequency of HPV infection (13.9\%) among control women in Morocco was intermediate, between the low prevalence found in Europe [17] and the high prevalence found in sub-Saharan Africa [18] and Latin America [19]. These differences in the prevalence of HPV in control women are consistent with the wide variations observed in cervical cancer incidence rates. HPV 16 was also by far the most common type among control women (51.3\% of HPV-positive control women) which is 
Table 6 Determinants of invasive cervical cancer: multivariate analysis with conditional logistic regression among 144 cases of cervical cancer and 288 controls

\begin{tabular}{|c|c|c|c|c|c|}
\hline & \multicolumn{2}{|l|}{ Cases } & \multicolumn{2}{|c|}{ Cases Controls } & \multirow[t]{2}{*}{ OR $(95 \% \mathrm{Cl})$} \\
\hline & No. & (\%) & No. & (\%) & \\
\hline Education & $n=134$ & & $n=273$ & & \\
\hline Educated & 21 & 15.7 & 118 & 43.2 & 1 \\
\hline Non-educated & 113 & 84.3 & 155 & 56.8 & $4.6(1.8-11.6)$ \\
\hline Husband's number of sexual partners & $n=129$ & & $n=269$ & & \\
\hline One & 67 & 51.9 & 210 & 78.1 & 1 \\
\hline Two and more & 62 & 48.1 & 59 & 21.9 & $2.9(1.3-6.7)$ \\
\hline No. of pregnancies & $n=141$ & & $n=276$ & & \\
\hline$\leq 3$ & 40 & 28.4 & 119 & 43.1 & 1 \\
\hline$>3$ & 101 & 71.6 & 157 & 56.9 & $1.7(1.1-4.3)$ \\
\hline \multicolumn{6}{|l|}{ Sexual intercourse during menstruation } \\
\hline No & 99 & 71.7 & 256 & 91.4 & 1 \\
\hline Yes & 39 & 28.3 & 24 & 8.6 & $9.9(2.8-35.6)$ \\
\hline History of Sexually Transmitted Infections & $n=138$ & & $n=270$ & & \\
\hline No & 123 & 89.1 & 262 & 97.0 & 1 \\
\hline Yes & 15 & 10.9 & 8 & 3.0 & $11.1(1.7-71.5)$ \\
\hline
\end{tabular}

Multicentre case-control study; Morocco; 2009-2012

in concordance with the worldwide distribution of HPV sub-types in cytologically normal women reported by the International Agency for Research on Cancer HPV in 2005 [20].

\section{Determinants of cervical cancer}

Because of the infection by high risk HPV is a necessary, but not a sufficient, cause for cervical cancer [3], it has been assumed that other factors contribute to modulate the risk of transition from cervical HPV infection to cervical cancer.

Our results suggest also that high parity increases the risk of cervical cancer. The explanatory mechanism is not clear [21] but a known suggestion says that pregnancy could influence HPV effects on the cervical epithelium through immunologic or hormone-dependent mechanisms.

The number of sexual partners was not a determinant in the development of cervical cancer, as reported in other World populations. This could be explained by the fact that most of the women in our study reported a unique lifetime sexual partner. In Morocco, polygamy is not a frequent practice among women, in this study $79.2 \%$ of the cases and $88.6 \%$ of controls women said that they were monogamous. However, polygamy is a common practice among men in our study $(48.1 \%$ of cases' sexual partners and $21.9 \%$ of controls' sexual partners). Geographic clusters of cervical and penile cancers [22], as well as elevated rates of cervical cancer among the wives of men with penile cancer $[23,24]$ raised the suspicion that a "male factor" might be important. This notion was supported by a follow-up study in which the wives of men previously married to cervical cancer patients were found to have elevated rates of cervical cancer compared to control wives [25].

Women who most likely belong to lower social classes, in which education and incomes are quiet low, are mainly subjects to cervical cancer [26, 27]. Also, cervical HPV infections appear to have historically been more prevalent in women of lower educational levels [28, 29].

In this study, sexual intercourse during menstruation was a determinant of cervical cancer. The explanatory mechanism is not clear, but a related finding was noted in Sichuan, China, where a strong protection was observed in women who abstained from sexual intercourse during menses [30].

In our study, history of sexually transmitted infections represents a risk factor for cervical cancer in Moroccan women. This result is consistent with other studies. Indeed, markers of exposure to other sexually transmitted infections have been found associated with cervical cancer repeatedly [31, 32].

Our study has many strong methodological points. We conducted a multicenter case-control study which improves the representativeness of cases of cervical cancer of the study compared to the cases of cervical cancer in Morocco. The two cancer centers of Rabat and Casablanca represent the first and largest oncology centers in 
Morocco. Before 2007, they were the only public centers for oncology in Morocco [33]. In our study we included only incident cases of cervical cancer which allowed us to avoid a possible selective survival bias. Also, controls were individually matched on age with cases which gave rise to the advantage of making the cases and controls more comparable except for the disease. At the same time, this matching allowed us controlling the effects of age. In our analysis, the matching was taken into account by using conditional logistic regression [34].

There are some limitations in the design of our study. The protocol was intended to identify a group of controls individually matched by age groups to the age distribution of the cases. The selection of cases was made in cancer centers; which attracts patients from a wide, ill-defined reference population. This is particularly true for cases of cervical cancer, which are referred for radiotherapy from distant areas in Morocco. Controls were derived from public outpatient gynecological hospitals and communal health-care centers with gynecological unit resulting in a group of predominantly urban residency compared with the cervical cancer cases. In Morocco, the residence area is an important indicator of the socioeconomic and educational levels [35] Women living in rural areas are of lower socioeconomic and lower educational levels than those residents in urban areas [35]. So, the residence area was carefully selected from all available indicators of socio-economic status as the strongest discriminants between cases and controls and adjustments were made in the analyses by including systematically as confounder variable the residence area.

\section{Conclusions}

In Morocco, HPV is the central cause of the cervical cancer cases. Currently, two HPV vaccines are available, a bivalent vaccine against HPV 16 and 18, and a tetravalent vaccine against HPV 6, 11, 16, and 18. In Morocco, the vaccine in theory could prevent $86.5 \%$ of cervical cancer cases. Despite the development of vaccination, screening programs remain a mainstay in the secondary prevention of cervical cancer. Identifying the factors, other than HPV, that contribute to the development of cervical cancer is essential.

The results of this study indicate that certain factors, such as low educational level, male sexual behavior, multiparity, sexual intercourse during menstruation, and history of sexually transmitted infections are the main lifestyle risk factors for cervical cancer in Morocco. This information could be used to install a program based on health education and to prioritize limited screening and treatment services to the benefit of women who have these specific characteristics putting them at an increased risk of cervical cancer.

\section{Abbreviations}

HPV: Human Papillomavirus; HPV-DNA: Human Papilomavirus - DNA; OR: Odds Ratio; PCR: Polymerase Chain Reaction

\section{Acknowledgments}

We wish to acknowledge first and foremost the field teams whose dedication was so important to the successful completion of this work: teams of the National Institute of Oncology, Gynecology Services of Hassan-II University Hospital-Fez, Centre of Oncology of IbnRochd University HospitalCasablanca, Obstetrics and Gynecology Services "Les Orangers" of IbnSina University Hospital-Rabat, Obstetrics and gynecology Services IbnRochd University Hospital-Casablanca, Primary Health care Centre "L'Océan" Rabat, Primary Health care Centre "Sidi Maarouf" and "Moulay Elhassan" Casablanca. We also thank the team of CNESTEN for their laboratory assistance for detection and identifying HPV type infection. We also thank the team of pathological anatomy laboratory of Hassan-II University Hospital-Fez, for histological evaluation of all PAP-smear material. We also acknowledge the collaboration of health authorities in Casablanca, Rabat and Fez for their support of this project and Pippa McKelvie-Sebileau for medical editorial assistance.

\section{Funding}

Financial support for this study was provided by the Hassan-II University HospitalFez, Faculty of Medicine and Pharmacy-Fez and "Agence Universitaire de la Francophone". The funding has been used to realize tumor biopsy specimen for cases and PAP-smear preparation for controls, and for HPV-DNA detection and typing.

No role of the funding in the design of the study and collection, analysis, and interpretation of data and in writing the manuscript.

\section{Availability of data and materials}

The datasets used and/or analysed during the current study are available from the corresponding author on reasonable request.

\section{Authors' contributions}

All authors read and approved the final manuscript. MB designed the study; coordinated acquisition, analysis, interpretation of data and writing article. $A A R$ and $C N$ contributed to study design and revising critically the article. SMP contributed to Analysis data and revising critically the article. ZQ; MA and MEM; analyzed and interpreted the patient data regarding the HPV infection. KZ and HEF analyzed and interpreted the histological patient data. $\mathrm{KB} ; \mathrm{MO}$ and $\mathrm{NA}$ analyzed and interpreted the clinical patient data. AFA; NM; $R B ; N B$ and $A B$ contributed to study design and revising critically the article.

\section{Competing interests}

The authors declare that they have no competing interests.

\section{Consent for publication}

Not applicable.

\section{Ethics approval and consent to participate}

Protocols were approved by Ethical Review Committees of the Fez Faculty of Medicine and the Hassan-II University Hospital. Because of the high illiteracy rate among this population, we have not been able to administer a written information sheet. Instead, an explanation of its content has been given to the patients and their verbal consent have been gathered.

\section{Publisher's Note}

Springer Nature remains neutral with regard to jurisdictional claims in published maps and institutional affiliations.

\footnotetext{
Author details

'Laboratory of Epidemiology, Clinical Research and Community Health, Faculty of Medicine and Pharmacy, University Sidi Mohammed Benabdellah, BP.1893Km 2.2 Route Sidi Harazem, Fez, Morocco. ²Pathological Anatomy Laboratory, CHU Hassan-II, Fez, Morocco. ${ }^{3}$ Biology Unit and Medical Research, National Center of Energy, Sciences and Nuclear Techniques (CNESTEN), Rabat, Morocco. ${ }^{4}$ Hospital "Les Orangers", CHU IbnSina, Rabat, Morocco. ${ }^{5}$ Faculty of Medicine and Pharmacy, University Mohammed V Souissi, Rabat, Morocco. ${ }^{6}$ Department of Radiotherapy, National Institute of Oncology, Rabat, Morocco. ${ }^{7}$ Department of Oncology-Radiotherapy, CHU IbnRochd, Casablanca, Morocco. ${ }^{8}$ Department of Gynecology and Obstetrics, CHU
} 
IbnRochd, Casablanca, Morocco. ${ }^{9}$ Faculty of Science and technology, Mohammedia, Morocco. ${ }^{10} \mathrm{Cancer}$ Registry of Casablanca, Casablanca, Morocco. ${ }^{11}$ Directorate of Epidemiology and Fight against Disease (DELM) Ministry of Health, Rabat, Morocco. ${ }^{12}$ Univ. Bordeaux, ISPED, Centre INSERM U897 - Epidemiologie-Biostatistique, F-33000 Bordeaux, France. ${ }^{13}$ CIC-EC7, Clinical and Epidemiological Research Unit, Institut Bergonié, Comprehensive Cancer Centre, Bordeaux, France.

\section{Received: 6 October 2015 Accepted: 12 June 2017}

\section{Published online: 20 June 2017}

\section{References}

1. Arbyn M, Castellsagué X, de Sanjosé S, Bruni L, Saraiya M, Bray F, et al. Worldwide burden of cervical cancer in 2008. Ann Oncol. 2011;22:2675-86.

2. Ferlay J, Shin H, Bray F, Forman D, Mathers C, Parkin DM. Estimates of worldwide burden of cancer in 2008: GLOBOCAN 2008. Int J Cancer. 2010;127:2893-917.

3. Walboomers JM, Jacobs MV, Manos MM, Bosch FX, Kummer JA, Shah KV, et al. Human HPV is a necessary cause of invasive cervical cancer worldwide. J Pathol. 1999:189:12-9.

4. Association Lalla Salma de lutte contre le Cancer 2012. Registre des cancers du grand Casablanca 2005-2007. http://uww.contrelecancer.ma/documents/registredes-cancers-de-la-region-du-grand-casab-2/. Accessed 10 Sept 2012.

5. Bennani B, Bennis S, Nejjari C, Ouafik L, Melhouf MA, El Rhazi K, et al. Correlates of HPV: a cross-sectional study in women with normal cytology in north-central Morocco. J Infect Dev Ctries. 2012;6:543-50.

6. Lalaoui K, El Mzibri M, Amrani M, Belabbas MA, Lazo PA. Human papillomavirus DNA in cervical lesions from Morocco and its implications for cancer control. Clin Microbiol Infect. 2003;9:144-8.

7. El Hamdani W, Amrani M, Attaleb M, Laantri N, Ennaji MM, Khyatti M, et al. EGFR, p16INK4a and E-cadherin immuno-histochemistry and EGFR point mutations analyses in invasive cervical cancer specimens from Moroccan women. Cell Mol Biol (Noisy-le-grand). 2010;56(Suppl):OL1373-84.

8. El Khair MM, Ennaji MM, El Kebbaj R, Mhand RA, Attaleb M, El Mzibri M. p53 codon 72 polymorphism and risk of cervical carcinoma in Moroccan women. Med Oncol. 2010;27:861-6.

9. Chaouki N, Bosch FX, Muñoz N, Meijer CJ, El Gueddari B, El Hazi A, et al. The viral origin of cervical cancer in Rabat, Morocco. Int J Cancer. 1998;75:546-54.

10. Asato T, Maehama T, Nagai Y, Kanazawa K, Uezato H, Kariya K. A. Large casecontrol study of cervical cancer risk associated with human papillomavirus infection in Japan, by nucleotide sequencing-based genotyping. J Infect Dis. 2004;189:1829-32.

11. Lee SH, Vigliotti VS, Vigliotti JS, Pappu S. Routine human papillomavirus genotyping by DNA sequencing in community hospital laboratories. Infect Agent Cancer. 2007;2:11.

12. Muñoz N, Bosch FX, de Sanjosé S, Herrero R, Castellsagué X, Shah KV, et al., International Agency for Research on Cancer multicenter cervical cancer study group. Epidemiologic classification of human HPV types associated with cervical cancer. N Engl J Med. 2003;348:518-27.

13. Clifford GM, Smith JS, Plummer M, Muñoz N, Franceschi S. Human HPV types in invasive cervical cancer worldwide: a metaanalysis. $\mathrm{Br} J$ Cancer. 2003;88:63-7.

14. Odida M, Sandin S, Mirembe F, Kleter B, Quint W, Weiderpass E. HPV types, HIV and invasive cervical carcinoma risk in Kampala, Uganda: a case-control study. Infect Agent Cancer. 2011:25:6-8.

15. Castellsagué X, Díaz M, de Sanjosé S, Muñoz N, Herrero R, Franceschi S, et al. International agency for research on cancer multicenter cervical cancer study group. Worldwide human HPV etiology of cervical adenocarcinoma and its cofactors: implications for screening and prevention. J Natl Cancer Inst. 2006;98:303-15.

16. Muñoz N, Castellsagué X, de González AB, Gissmann L. Chapter 1: HPV in the etiology of human cancer. Vaccine 2006;24Suppl 3:S3/1-10.

17. de Sanjose S, Almirall R, Lloveras B, Font R, Diaz M, Muñoz N, et al. Cervical human HPV infection in the female population in Barcelona. Spain SexTransmDis. 2003;30:788-93.

18. Thomas JO, Herrero R, Omigbodun AA, Ojemakinde K, Ajayi IO, Fawole A, et al. Prevalence of HPV infection in women in Ibadan, Nigeria: a population-based study. Br J Cancer. 2004;90:638-45.

19. Molano M, Posso H, Weiderpass E, van den Brule AJ, Ronderos M, Franceschi S, et al. Prevalence and determinants of HPV infection among Colombian women with normal cytology. Br J Cancer. 2002;87:324-33.
20. Clifford GM, Gallus S, Herrero R, Muñoz N, Snijders PJ, Vaccarella S, et al. IARC HPV Prevalence Surveys Study Group. Worldwide distribution of human HPV types in cytologically normal women in the International Agency for Research on Cancer HPV prevalence surveys: a pooled analysis. Lancet. 2005;366:991-8.

21. Castle PE, Walker JL, Schiffman M, Wheeler CM, ALTS Group. Hormonal contraceptive use, pregnancy and parity, and the risk of cervical intraepithelial neoplasia 3 among oncogenic HPV DNA-positive women with equivocal or mildly ab normal cytology. Int J Cancer. 2005;117:1007-12.

22. Cartwright RA, Sinson JD. Carcinoma of penis and cervix. Lancet. 1980;1:97.

23. Hellberg D, Nilsson S. Genital cancer among wives of men with penile cancer. A study between 1958 and 1982. Br J Obstet Gynaecol. 1989;96(2):221-5.

24. Smith PG, Kinlen $L J, G c$ W, Adelstein AM. Fox AJ. Mortality of wives of men dying with cancer of the penis. Br J Cancer. 1980;41:422-8.

25. II K. Venereal factors in human cervical cancer: evidence from marital clusters. Cancer. 1977;39:1912-9.

26. Brinton LA, Fraumeni JF Jr. Epidemiology of uterine cervical cancer. J Chronic Dis. 1986:39:1051-65.

27. Parikh S, Brennan P, Boffetta P. Meta-analysis of social inequality and the risk of cervical cancer. Int J Cancer. 2003;105:687-91.

28. Hildesheim A, Gravitt P, Schiffman MH, Kurman RJ, Barnes W, Jones S, et al. Determinants of genital human HPV infection in low-income women in Washington, D.C. Sex Transm Dis. 1993;20:279-85.

29. Stone KM, Karem KL, Sternberg MR, McQuillan GM, Poon AD, Unger ER, et al. Seroprevalence of human HPV type 16 infection in the United States. J Infect Dis. 2002:186:1396-402.

30. Peng H, Liu S, Mann V, Rohan T, Rawls W. Human HPV types 16 and 33, herpes simplex type 2 and other risk factors for cervical cancer in Sichuan Province, China. Int J Cancer. 1991;47:711-6.

31. Smith JS, Muñoz N, Franceschi S, Eluf-Neto J, Herrero R, Peeling RW. Chlamydia trachomatis and cervical squamous cell carcinoma. JAMA. 2001;285:1704

32. Smith JS, Bosetti C, Muñoz N, Herrero R, Bosch FX, Eluf-Neto J. Chlamydia trachomatis and invasive cervical cancer: a pooled analysis of the IARC multicentric case-control study. Int J Cancer. 2004;111:431-9.

33. Association Lalla Salma de lutte contre le Cancer 2009. Rapport Volumes 3 : Etude des stades de diagnostic et des résultats des traitements des cancers au Maroc.

34. Kleinbaum DG. Logistic regression: a self- learning text. Springer-Verlag 1994. ISBN 978-1-4419-1742-3. http://www.springer.com/us/book/9781441917416.

35. Haut-Commissariat au Plan 2008. National survey on income and living standards of households 2006/2007.

\section{Submit your next manuscript to BioMed Central and we will help you at every step:}

- We accept pre-submission inquiries

- Our selector tool helps you to find the most relevant journal

- We provide round the clock customer support

- Convenient online submission

- Thorough peer review

- Inclusion in PubMed and all major indexing services

- Maximum visibility for your research

Submit your manuscript at www.biomedcentral.com/submit
) Biomed Central 